Revista de Comunicación y Salud, 2020, Vol. 10, no 2, pp. 81-108

Editado por Cátedra de Comunicación y Salud

ISSN: 2173-1675

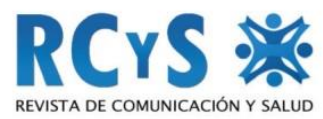

Enviado 15/08/2020

Aprobado 13/10/2020

\title{
INFOGRAFÍAS SOBRE CALIDAD DE VIDA DIFUNDIDAS POR EL GOBIERNO DE MÉXICO EN EL SITIO “TODO SOBRE EL COVID-19”
}

\section{Quality of life infographics on widespread for the Government of Mexico on the site "Todo sobre el COVID-19"}

\author{
Paola Eunice Rivera Salas': \\ Benemérita Universidad Autónoma de Puebla. México \\ paola.rivera@correo.buap.mx
}

\section{Resumen}

La Calidad de Vida es un indicador que mide la condición en la que viven los individuos de acuerdo con el grado de satisfacción de sus necesidades relacionadas con su salud, su entorno y el espacio en que se tornan productivos. Esta investigación tuvo por objetivo identificar la presencia de la Calidad de Vida en la información contenida en los infográficos que publicó el Gobierno de México en el sitio "Todo sobre el COVID-19". El diseño metodológico para este trabajo fue cuantitativo, descriptivo, transversal y no experimental. La muestra se integró por 150 infográficos publicados por el Gobierno de México durante la actual pandemia generada por el virus SARCoV-2, en el sitio electrónico ya mencionado. La recuperación de información se realizó mediante una guía de observación. Las variables de interés fueron Calidad de Vida e Infografías. Como principales hallazgos se aprecia que los infográficos socializan información sobre la Calidad de Vida vinculada a la pandemia. El ámbito de la Calidad de Vida más abordada es el de la salud. No obstante, se requiere incrementar mensajes sobre temáticas como la salud mental y el manejo de estrés laboral durante el confinamiento. En cuanto a los infográficos como unidades informativas, su estructura es organizada y estética. Sin embargo, $40 \%$ no cuentan con fuentes de información, lo que puede poner en duda la calidad de la información que contienen. Es importante que los grandes emisores como los Gobiernos, ponga especial énfasis en la construcción de piezas comunicativas adecuadas para atender de forma eficiente las necesidades de información.

Palabras clave: Calidad de vida; Calidad de vida laboral; Calidad de vida social; Calidad de vida en salud; Coronavirus; Infografía

\footnotetext{
Abstract

${ }^{1}$ Autora para correspondencia: Paola Eunice Rivera Salas, Benemérita Universidad Autónoma de Puebla, paola.rivera@correo.buap.mx.
} 
Infografías sobre calidad de vida difundidas por el gobierno de México en el sitio "Todo sobre el COVID-19"

Quality of Life is an indicator that measures the condition in which individuals live according to the degree of satisfaction of their needs related to their health, their environment, and the space in which they become productive. The objective of this research was to identify the presence of Quality of Life (QoL) in the information contained in the infographics published by the Government of Mexico on the site "Todo sobre COVID-19." The methodological design for this work was quantitative, descriptive, cross-sectional, and non-experimental. The sample was made up of 150 infographics published by the Government of Mexico during the current pandemic generated by the SARCoV-2 virus, on the website. Information retrieval was carried out using an observation guide. The variables of interest were QoL and Infographics. As the main findings, it is appreciated that the infographics socialize information about QoL linked to the pandemic. The area of QoL most addressed is health. However, it is necessary to increase messages on topics such as mental health and the management of work stress during confinement. Regarding infographics as informative units, their structure is organized and aesthetic. However, $40 \%$ do not have sources of information, which may cast doubt on the quality of the information they contain. Large issuers such as governments must take special emphasis on the construction of adequate communication pieces to efficiently meet information needs.

Keywords: Quality of life; Quality of work life; Quality of social life; Quality of life in health; Coronavirus; Infographic.

\section{Cómo citar el artículo}

Rivera Salas, P. E. (2020). Infografías sobre calidad de vida difundidas por el gobierno de México en el sitio "Todo sobre el COVID-19". Revista de Comunicación y Salud, 10 (2), 81-108. doi: https://doi.org/10.35669/rcys.2020.10(2).81-108

\section{INTRODUCCIÓN}

Con la llegada a México del virus SARCoV-2, conocido como COVID-19 en febrero de 2020, el Gobierno de México Instauró mediante la Secretaría de salud la Jornada Nacional de Sana Distancia (JNSD). Esta jornada se implementó con el objetivo de reducir el número de contagios generados por este virus. Desde su inicio, en marzo de 2020, la jornada se centró en que la sociedad contribuyera a que la curva epidémica del comportamiento de los casos fuera lo más plana posible. Para ello, el Estado Mexicano implementó una campaña en distintos medios de comunicación y a través de diversos formatos para orientar a la población y persuadirla sobre la importancia de sus acciones para lograr este objetivo.

Fue así como el Gobierno de México crea el sitio "Todo sobre el COVID-19". En este espacio virtual, las piezas comunicativas que se socializaron de manera oficial y que estuvieron vinculadas no solo a la difusión de información sobre el virus, sino también a cómo permanecer saludable durante este periodo de contingencia. Siendo uno de los formatos más socorridos para esta campaña fue el uso de infográficos vinculados a 
Infografías sobre calidad de vida difundidas por el gobierno de México en el sitio

"Todo sobre el COVID-19"

diferentes temáticas relacionadas con esta pandemia. Los mensajes que se plasmaron van encaminados a contribuir a la Calidad de Vida de los receptores durante la JNSD.

Es así como el propósito de la investigación fue determinar la presencia de la Calidad de Vida, y sus diferentes ámbitos, en la información que se integra en los infográficos que el Gobierno de México publicó en la página "Todo sobre el COVID-19". Esta investigación resulta relevante ya que es importante documentar las experiencias que se derivan de los productos comunicativos que los gobiernos están proporcionando ante una pandemia sin precedentes en el mundo actual. Más aun, cuando estos actores son los responsables de tomar y ejecutar medidas adecuadas para salvaguardar la seguridad de todos los ciudadanos que viven en el espacio geográfico que norman. Entonces, se torna necesario atender las necesidades de información que tienen los ciudadanos para apoyar en los cursos de acción que conlleven a mejorar la situación de la comunidad.

\subsection{Calidad de vida y sus ámbitos}

Durante el siglo pasado, las agencias y organismos internacionales plantearon la inquietud por establecer cuáles eran las condiciones mínimas deseables para que cualquier ser humano pudiera no sólo sobrevivir, sino tener un estándar adecuado, bajo el cual cubriera sus necesidades básicas, sin dejar de lado elementos vinculados al bienestar emocional. En este contexto es que surge el concepto de Calidad de Vida.

Inicialmente, la Organización Mundial de la Salud (2002) definió este término en como la percepción que un individuo tiene sobre su situación personal, y que depende de dónde reside, el marco cultural y de valores en el que interactúa. Al mismo tiempo, toma en cuenta las metas, expectativas, estándares y preocupaciones que cada persona tiene dado su entorno.

A partir de esta propuesta, distintos autores han desarrollado una conceptualización del término. No obstante, muchos de ellos han coincidido que la Calidad de Vida es un concepto multidimensional que conjunta aspectos objetivos y subjetivos de la vida de un individuo (Segurado Torres y Agulló Tomás, 2002; Ardilla, 2003; González Celis, 2005; Salazar et al, 2005; Baldi, 2010; Ruvalcaba Romero, Salazar Estrada y Fernández Berrocal, 2012).

Alves, Cirera y Carlos (2013) señalaron que hay aspectos que la componen que son fácilmente medibles como el tipo de vivienda que tiene o el acceso a servicios públicos. Sin embargo, la Calidad de Vida involucra aspectos subjetivos que tienen que ver más bien con la personalidad como son la satisfacción y las prioridades que cada persona tiene. Es así, cómo se han delimitado distintos ámbitos de incidencia de concepto dada la incidencia que tiene la vida de un individuo.

Este concepto también incluye elementos vinculados al desarrollo humano, el reconocimiento que las personas consideran ha obtenido por el trabajo que realizan, el sistema de valores que se aplica de manera cotidiana en su entorno, así como el afecto

Revista de Comunicación y Salud, 2020, Vol. 10, nº 2, pp. 81-108 
Infografías sobre calidad de vida difundidas por el gobierno de México en el sitio

"Todo sobre el COVID-19"

que perciben los individuos reciben en sus relaciones con otros (Salas, C. y Garzón, M. O., 2013). Es así como se visualizan las dimensiones: Calidad de Vida Social, Calidad de Vida relacionada con la Salud y Calidad de Vida Laboral (Robles-Espinoza, A.I., et al, 2016).

\subsubsection{Calidad de Vida en el trabajo o laboral}

La Calidad de Vida en el trabajo o laboral se vincula con las experiencias que se obtienen a partir de ser parte de la población económicamente activa. Esto implica determinar los efectos que la dinámica de trabajo tiene en la existencia del trabajador. Al mismo tiempo, de manera recíproca, tiene efectos en los resultados que obtienen las organizaciones a partir del nivel de desempeño que los trabajadores alcanzan (Alves, Cirera y Carlos, 2013).

Swany, Nanjundeswaraswamy y Rashmi (2015) mencionan que este ámbito de la Calidad de Vida puede concebirse como el grado de satisfacción que un empleado tiene a partir de cubrir sus necesidades laborales y personales como consecuencia del trabajo que realiza, al tiempo que alcanza sus objetivos que la organización que lo emplea le ha asignado.

Así que, este ámbito, hay diferentes aspectos objetivos que se han abordado en diversos estudios -consulte la figura 1-, en los últimos años han destacado aspectos subjetivos, a saber: Promoción de la dignidad y el crecimiento humanos, trabajo colaborativo, participación en la toma de decisión sobre cambios laborales, y la aceptación de la diversidad de las personas como un factor que contribuye al logro de las metas organizacionales (Srivastava y Kapur, 2014, p. 55).

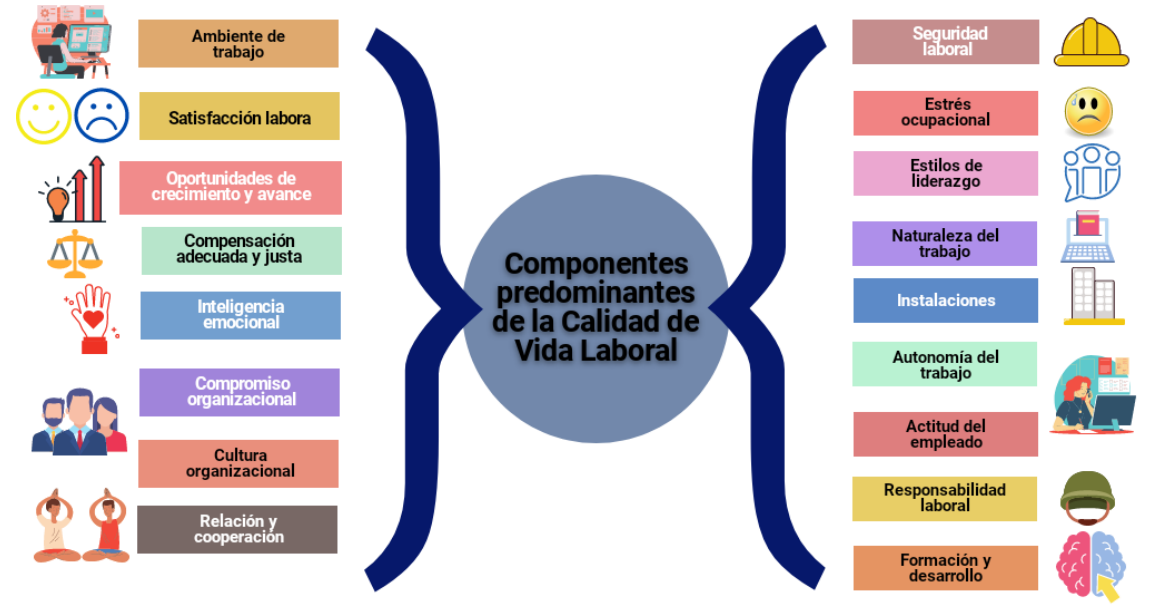

Figura 1. Componentes predominantes de la Calidad de Vida Laboral.

Fuente: Elaboración propia basada en Nanjundeswaraswamy y Sandhya (2016).

Los estudios sobre este ámbito de la Calidad de Vida se han enfocado no solo al trabajo como tal, sino al trabajo remoto. Martínez Gamarra y Ros Mar (2010) y 
Infografías sobre calidad de vida difundidas por el gobierno de México en el sitio

"Todo sobre el COVID-19"

Camacho y Higuita (2012) han señalado que, si bien el este tipo de trabajo representa para muchas empresas mayores niveles de productividad, puede amedrentar la Calidad de Vida de los trabajadores, dada la falta de administración del tiempo, el poco contacto con sus pares de la organización e incluso la disminución de tiempo de calidad con los miembros de su familia.

Esta área de incidencia de la Calidad de Vida Laboral ha cobrado espacial interés a partir de la contingencia sanitaria derivada del COVID-19. El trabajo remoto, entendido como realiza total o parcialmente en un lugar alternativo que no sea el lugar predeterminado como sede de la organización (Internacional Labour Organization, 2020), ha crecido exponencialmente y de forma obligada. Muchos trabajadores en el mundo han tenido que migrar a esta modalidad, pero carecen de preparación o experiencia previa al respecto.

En este sentido, la Organización Internacional del Trabajo en América Latina (2020) ha enfatizado en la importancia de realizar ajustes en materia laboral relacionadas con la Calidad de Vida, que implican la conservación del empleo y adoptar y asignar espacios de trabajo seguros. Asimismo, ha subrayado la necesidad de contrastar algunas problemáticas que están generando en esta pandemia como son: el estrés resultante de la sobrecarga laboral y de otras actividades -como el cuidado y educación de menores o la atención a adultos mayores-, las condiciones de trabajo, inseguridad respecto a las relaciones laborales actuales y futuras.

\subsubsection{Calidad de Vida relacionada con la Salud}

La salud es otro ámbito que engloba el concepto de la Calidad de Vida. Esta dimensión retoma el valor que los individuos le otorgan a su vida, considerando su duración y las oportunidades que brinda el entorno para tener un nivel de bienestar (Patrick y Erickson, 1993). Más adelante, autores como Shumaker y Naughton (1995) y Wu (2000) definen este ámbito incluyendo la promoción de la salud y como esta ayuda a los sujetos a alcanzar sus metas personales.

Posterior, Urzúa (2010) subraya la importancia de situar este concepto más allá del campo de la medicina, dada su incidencia en el contexto social. Karimi y Brazier (2016) exponen que este concepto se asocia a la medición del estado de salud que tiene una persona dado una serie de criterios propuestos. También, se refiere este concepto a como la condición de estar o no estar saludable afecta la propia Calidad de Vida que tiene una persona.

Este ámbito de la Calidad de Vida, como establecen Sanjuán y Ávila (2016) puede verse afectado por factores que alteren la salud física y mental que conlleven a un declive paulatino, cómo es la falta de sueño, escasa actividad física, el dolor continuo, deshidratación o una alimentación incorrecta. Igualmente, otros aspectos de índole psicológico como la falta de motivación, visualización de metas o poca capacidad de afrontar problemas o situaciones extraordinarias -como un confinamiento- puede amedrentar la Calidad de Vida en salud, tanto física como mental.

Revista de Comunicación y Salud, 2020, Vol. 10, nº 2, pp. 81-108 
Infografías sobre calidad de vida difundidas por el gobierno de México en el sitio

"Todo sobre el COVID-19"

Existen otras condiciones que afectan la Calidad de Vida en salud. Angulo Hurtado y Ramírez Quintana (2016) mencionan que se ha determinado que el nivel de este ámbito de la Calidad de Vida disminuye con la labor de cuidar a otras personas -adultos mayores, personas con capacidades diferentes, enfermo, por mencionar algunos-, trayendo como consecuencias el aislamiento social, la planeación de actividades restringidas en función de quien cuidamos, y anteponiendo el cuidado de la salud física de otros por la de uno mismo.

En general, este ámbito de la Calidad de Vida ha tomado relevancia pues los individuos evalúan el costo-beneficio de adoptar prácticas, recibir tratamientos 0 atender un seguimiento médico considerando el nivel de incidencia que tendrá en su nivel de bienestar, y con base en ello toman decisiones e invierten recursos (CáceresManrique, Parra-Prada y Pico-Espinosa, O. J. , 2018).

Lopera (2020) incluyó otros elementos que pueden afectar el nivel de Calidad de Vida en este ámbito, como son las enfermedades, los tratamientos a los que se somete el individuo, los accidentes, o incluso las políticas de salud que hay en su país y le permiten alcanzar cierto estándar de bienestar -la vacunación gratuita, el acceso a servicios de salud, campañas de prevención de enfermedades, entre otras-.

Como otras dimensiones de la Calidad de Vida, esta dimensión ha sido retomada recientemente, pues el aislamiento y la nueva normalidad ha dejado claro lo esencial que es el cuidado personal, tanto físico como mental, durante la contingencia (Rivera Alvarado, 2020). Entonces, las prácticas saludables y las medidas de seguridad se han posicionado como un tema de interés social.

\subsubsection{Calidad de Vida Social}

Un ámbito de la Calidad de Vida que se vincula con su situación en el espacio en que vive es la llamada Calidad de Vida social. Desde una visión económica, los niveles óptimos en este ámbito se alcanzan cuando el individuo puede cubre sus necesidades fundamentales mediante el uso de recursos que hay en su entorno. Se ha trabajado este concepto desde el punto de vista del grado de confort y seguridad que otorga el medio en que vive a sus habitantes dadas las demandas que tienen (Abaleron, 1998; Lindenboim, 2000). También, se ha abordado desde la urbanización de los territorios y sus efectos en los seres humanos (Leva, 2005).

Algunos elementos que afectan este ámbito de calidad de vida son la poca o nula integración social, la ausencia de solidaridad y las pocas o nulas redes sociales creadas por el individuo (Lee, 2015).

Pero este concepto va más allá, pues incluye la forma en que las personas pueden participar en la vida social y cultural de su comunidad, realizando acciones que contribuyan al mejoramiento del bienestar individual y colectivo. Por ello, se vincula con otros conceptos como la cohesión, el empoderamiento y la inclusión social como parte

Revista de Comunicación y Salud, 2020, Vol. 10, nº 2, pp. 81-108 
Infografías sobre calidad de vida difundidas por el gobierno de México en el sitio

"Todo sobre el COVID-19"

de los requisitos que el individuo debe percibir como cubiertos para satisfacer sus necesidades en este sentido (Tomlinson, Walker y Foster, 2016).

Otros elementos están más relacionados con las facilidades que el sistema político les proporciona. De ahí que, sea indispensable que el Estado, considerando sus propias funciones, junto con otras organizaciones, regulen de las condiciones socioeconómicas para abordar las necesidades prioritarias de los ciudadanos, fortalecer la confianza y la dignidad en la sociedad, honrar los valores y normas de todos los grupos que forman parte de la comunidad (Danilova, Kovrigina y Khuziakhmetov, 2020).

En los últimos meses, la Calidad de Vida Social ha estado presente dada la contingencia sanitaria, pues este proceso ha evidenciado la falta de condiciones suficientes para el aislamiento. En este sentido, Rivera Alvarado (2020) señala que el padecimiento de este virus no se visualiza de igual forma en los distintos estratos sociales. Por lo que, esto puede incidir en la percepción de la Calidad de Vida Social que tiene los individuos.

\subsection{Infografías}

Las infografías son productos comunicativos que difunden mensajes de manera sucinta. Al mismo tiempo, concentran gran cantidad de información comprensible y sencilla. Considerando los datos que se plasma en ellos, en algunos casos, se ocupa para revelar la causa y el efecto de algún fenómeno. En otros casos, permite ver la evolución de ciertos parámetros o estadísticos de interés como los concernientes a la demografía, las finanzas, el mercado, entre otros. No obstante, independientemente de la temática, tiene una clara función de educar al receptor (Saroja, 2020).

Esta pieza comunicativa transmite datos con elementos visuales y comprensibles; estimulando el interés de los lectores por su contenido creativa y presentación compacta (Ponce, Rangone y Funes, 2015). Se puede consumir en formato impreso y digital. Por lo que se convierte en una herramienta complementaria para explicar aspectos específicos de un tema en un espacio virtual (Roney, Menjívar y Morales, 2015); o bien, ser expuesta en presentaciones orales presenciales, o en espacios donde cualquier transeúnte puede consultarla.

La infografía es una forma de comunicación que requiere un adecuado balance entre el texto y la imagen. Su presentación debe ser atractiva y agradable a la vista; pero esta característica no debe estar por encima de elementos como la veracidad de la calidad de la información. Es decir, los datos expuestos deben sustentarse en fuentes confiables, que el receptor observe como parte del contenido del infográfico (Siricharoen y Siricharoen, 2015).

Según Madurga (2016), las principales ventajas que este componente gráfico representa son: 1) Permite escanear rápidamente la información que contiene; 2) Por su extensión, su lectura es amena; 3) El contenido es fácil de comprender y asimilar; 4) De gran impacto en medios digitales porque captan el tráfico y se comparten fácilmente.

Revista de Comunicación y Salud, 2020, Vol. 10, no 2, pp. 81-108 
Infografías sobre calidad de vida difundidas por el gobierno de México en el sitio

"Todo sobre el COVID-19"

Arum (2017) precisa que el infográfico debe someterse a un proceso de evaluación antes de su socialización, para garantizar que la organización de las imágenes y texto sea adecuada para las audiencias y que haya calidad en la información que se incluye. Siguiendo estas recomendaciones, el infográfico se convierte en una herramienta poderosa para transmitir información, sin importar lo compleja que puede ser, los usuarios captarán el mensaje.

No hay que perder de vista, como lo mencionan Sanz y Castejón (2018) que los infográficos responden a una necesidad informativa, brindando datos que responden a los criterios de veracidad, claridad y síntesis. Siendo esta la función esencial que cumplen estas piezas comunicativas.

\subsection{La Calidad de vida en Infográficos sobre COVID-19 en México}

Desde inicios del siglo XX, las infografías ya eran muy utilizadas por la comunidad científica para explicar procesos o exponer información. En los años 30's del siglo pasado este formato se introduce gradualmente en los medios de comunicación. Diversas agencias y organizaciones internacionales han recurrido al uso de infográficos para dar a conocer información. Tan solo en el 2016, el sitio web de la Organización Mundial de la Salud - Europa reportó que las infografías representaron más de 50,000 vistas (Nielsen, 2017).

Con el crecimiento exponencial de la producción de infográficos, las temáticas que se han abordado han sido muy diversas. Los infográficos se han utilizado no solo en el periodismo; la mercadotecnia, la educación y hasta la comunicación gubernamental han recurrido a esta pieza de comunicación para conectar con sus audiencias (Català Domínguez, 2018). Siendo así que, la Calidad de Vida y sus ámbitos han quedado plasmados en estas modalidades difusión de mensajes.

Así, por ejemplo, la infografía ha demostrado ser una opción para las compañías farmacéuticas y organizaciones vinculadas con la salud, puesto que exponen información médica que puede ser difundida a diferentes audiencias (Patel et al., 2020; Rivera-Salas, 2019). En este sentido, Buljan et al (2017) concluyeron que, en temas de salud y desarrollo humano, los receptores encuentran más entretenido y educativo los contenidos expuestos en una infografía que en un texto tradicional.

Muñoz del Bosque (2017) considera que los infográficos pueden apoyar en la difusión de información relacionada con la Calidad de Vida en el ámbito de la salud, centrándose en temáticas como la difusión sobre las características de una enfermedad, así como su tratamiento y/o control. Además, se pueden abordar medidas para conservar la salud integral del individuo al socializar información sobre el cuerpo humano y su funcionamiento.

Desde el ámbito de lo social, compartir información en infografías trae consigo diversos beneficios al proporcionar datos concisos sobre una temática específica. Cox y

Revista de Comunicación y Salud, 2020, Vol. 10, nº 2, pp. 81-108 
Infografías sobre calidad de vida difundidas por el gobierno de México en el sitio

"Todo sobre el COVID-19"

De Goeij (2020) descubrieron que, incluso en la administración de recursos financieros, el conocimiento del tema mediante los infográficos apoya a los consumidores a tomar decisiones del uso del dinero y otros activos, primordialmente a aquellos que contaban con mejor nivel de escolaridad.

Entonces, el infográfico es un formato que se consulta como una opción para obtener información. La pandemia derivada del nuevo coronavirus SARS-CoV-2 no ha sido una excepción. A partir de la llegada de este virus a América Latina, los internautas han consultado continuamente infográficos sobre el COVID-19. Desde la segunda semana de marzo y hasta el mes de julio de 2020, las estadísticas demuestran que un recurso de alta demanda en el ambiente digital (Google Trends, 2020a).

Para el caso de México, el Gobierno Federal creó el espacio "Todo sobre el COVID19 " con el fin de proporcionar infográficos enfocados en el SARS-CoV-2, que orientan a la población mexicana sobre las medidas de seguridad y prácticas saludables vinculadas a conservar su Calidad de Vida -desde sus distintas dimensiones- durante la contingencia de salud. Este sitio presentó constante accesos de manera continua desde su inserción a finales de marzo a junio de 2020 (Google Trends, 2020b).

Cabe señalar que, el Gobierno de México implementó este espacio para concentrar toda la información relacionada con la pandemia y apoyar a la JNSD. Esto implica varios tipos de productos comunicativos -como folletos, videos, manuales, infografías, carteles, entre otros- dirigidos a diversas audiencias. La campaña de difusión de la JNSD tiene como elemento central al personaje Susana Distancia, una popular heroína en dibujo animado -con más de 70,000 seguidores en Twitter-, que busca concientizar a la población sobre las medidas básicas que hay que tomar para evitar contraer el COVID-19 (El Universal, 2020).

Los infográficos publicados también incluyeron elementos vinculados a la imagen institucional del Gobierno de México y sus dependencias, así como datos para que el usuario obtenga mayor orientación vía telefónica y hasta los espacios que el Estado tiene en redes sociales para solventar dudas de la población en general sobre la pandemia. Algunos de ellos, incluyen la fecha de publicación y etiquetas relacionadas con el COVID-19 (Gobierno de México, 2020). Estos elementos se muestran en la figura 2. 


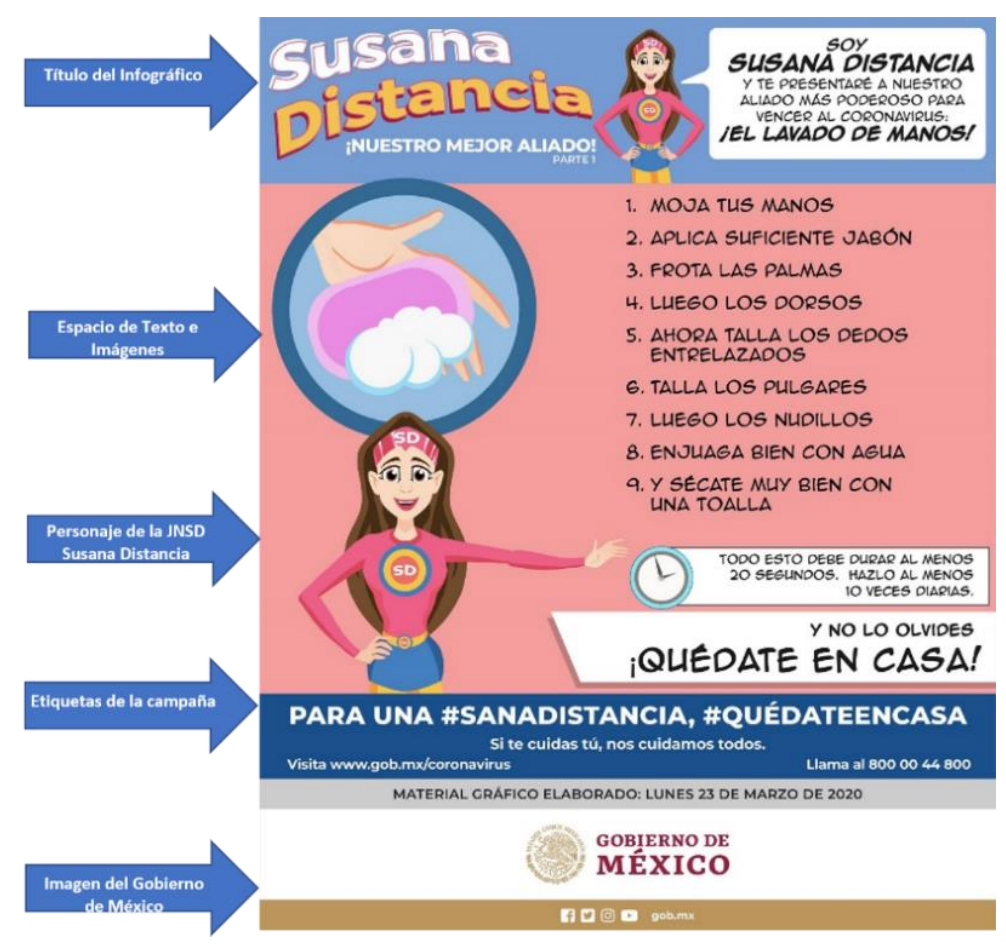

Figura 2. Infografía publicada en el sitio "Todo sobre el COVID-19" y sus algunos de sus elementos.

Fuente: Elaboración propia con la información del Gobierno de México (2020)

De forma alterna, se socializaron estas piezas comunicativas en sus espacios en redes sociales, mediante medios tradicionales y en espacios públicos en formato impreso. Lo anterior, como parte de la estrategia de comunicación que el gobierno del Lic. Andrés Manuel López Obrador se propuso al inicio de su gestión, que tiene como público objetivo a los 55 millones de mexicanos cibernautas, y a 75 millones de habitantes que consultan información por medios tradicionales (García Soto, 2019).

\section{OBJETIVOS}

Objetivo General.

- Identificar la presencia de la Calidad de Vida en la información contenida en los infográficos que publicó el Gobierno de México en el sitio "Todo sobre el COVID-19".

Objetivos Específicos:

A. Determinar los mensajes que se difunden en los infográficos sobre cada uno de los ámbitos de la Calidad de Vida: Salud, Vida Laboral y Vida Social.

B. Delimitar el contenido que se incluye en los infográficos sobre el COVID-19 que fueron socializados por el Estado Mexicano. 
Infografías sobre calidad de vida difundidas por el gobierno de México en el sitio

"Todo sobre el COVID-19"

\section{METODOLOGÍA}

Para atender a los objetivos de la investigación, se utilizó un enfoque cuantitativo para medir a través de datos cuantificables la frecuencia con la que se presenta las variables y categorías de interés. También, se aplicó un método descriptivo y no experimental, debido a que solo se muestran las características que presenta los objetos de estudio, sin incidir en variable alguna. Asimismo, se implementó un diseño transversal debido a que la recuperación de información se hizo de una sola vez, a finales del mes de julio, momento en que el México, la fase 3 comenzó a ser superada en varios estados del país, para pasar a un nuevo esquema de normalidad.

Para delimitar los objetos de estudio se revisó la página electrónica que el Gobierno de México creó para orientar a la población sobre el nuevo coronavirus SARS-CoV-2. Este sitio se denomina "Todo sobre el COVID-19". En dicho sitio, la información se distribuyó por temáticas de interés -consulte la figura 3 del anexo 1-. De primera mano, se identificó que el espacio virtual incluye un total de 320 infografías que proporcionan información sobre la pandemia a distintos públicos.

Una vez que se revisaron los infográficos, se detectó que 170 de estos son una versión traducida a alguna de las 72 lenguas indígenas que se hablan en el territorio mexicano. Dichos infográficos mantienen tanto el diseño como la distribución de contenidos (Gobierno de México, 2020). Aunado a ello, se visualizó que no todos los infográficos publicados en español fueron traducidos. Hay que subrayar que el español es la lengua materna de casi el 95\% de los habitantes en México (Instituto Nacional de Estadística, Geografía e Informática, 2015). Por ello, solo se consideraron como parte de la muestra para este estudio únicamente a los 150 infográficos publicados en español en el sitio mencionado. Las infografías que se observaron para esta investigación y el título del espacio en que se ubicaron en el sitio mencionado con antelación se precisan en la tabla 1.

Tabla 1. Infografías incluidas en el estudio por temática de interés según el sitio "Todo sobre el COVID-19"

\begin{tabular}{|l|r|}
\hline Temática de Interés & $\begin{array}{l}\text { No. de infografías } \\
\text { observadas }\end{array}$ \\
\hline Información general sobre el COVID-19 & 18 \\
\hline Entorno Escolar & 4 \\
\hline Entorno Laboral & 5 \\
\hline Recomendaciones para el personal de salud & 15 \\
\hline Sana Distancia & 29 \\
\hline Mitos y realidades sobre el COVID-19 & 4 \\
\hline Uso de cubrebocas & 7 \\
\hline Otros entornos & 15 \\
\hline Los porqués de las medidas de prevención & 7 \\
\hline Acciones con perspectiva de género & 2 \\
\hline Salud mental & 19 \\
\hline Niños y niñas & 1 \\
\hline
\end{tabular}

Revista de Comunicación y Salud, 2020, Vol. 10, no 2, pp. 81-108 
Infografías sobre calidad de vida difundidas por el gobierno de México en el sitio

"Todo sobre el COVID-19"

\begin{tabular}{|l|r|}
\hline Salud materna & 2 \\
\hline Juntos por el trabajo & 11 \\
\hline Datos personales seguros COVID-19 & 11 \\
\hline
\end{tabular}

Fuente: Elaboración propia basada en el sitio Todo sobre el COVID-19 (Gobierno de México, 2020).

Las variables de interés para este documento fueron Calidad de Vida, que se conceptualiza como la valoración que tiene cualquier individuo sobre de diversos aspectos de su vida que incluyen satisfactores de tipo laboral, social y de salud personal. Las dimensiones que se determinaron en este caso fueron Calidad de Vida relacionada con la Salud, Calidad de Vida Laboral y Calidad de Vida Social.

Otra variable de interés fue la Infografía -o infográfico-, definida como una unidad de información que combina de forma balanceada texto e imágenes, cuya función es difundir datos validados correspondientes a una amplia gama de temáticas. Las dimensiones que se delimitaron para esta variable fueron mensaje, función y estructura de la infografía.

Para el sustento de la investigación y la construcción del instrumento, se diseñó una estrategia de búsqueda, a partir de las palabras clave determinadas en función de las variables de interés. Posteriormente, se ubicaron artículos de investigación correspondientes a los últimos 5 años -2015 a 2020- en bases de datos y portales de difusión científica como Google Scholar, Dialnet, Scielo y EBSCO. La estrategia de búsqueda utilizada se desglosa en la figura 4 del anexo 1.

De inicio, los portales mencionados arrojaron más de 82000 resultados producto de las diferentes combinaciones de búsqueda realizadas. Luego, con la valoración de los títulos y el resumen, se descartaron un gran número de documentos, quedando para su resguardo únicamente 123 artículos de investigación a texto completo. Sin embargo, una vez que se revisaron elementos como la introducción, la discusión y las conclusiones, se conservaron únicamente 56 artículos de investigación. Hay que puntualizar que, varios de estos documentos permitieron identificar artículos que no fueron publicados en el periodo de revisión propuesto, pero que son citados de forma recurrente; como por ejemplo Ardila (2003) y Segurado Torres y Agulló Tomás (2002). Con la información copilada en matrices en las que se concentraron los elementos teóricos, metodologías, principales hallazgos y conclusiones de cada artículo, se operacionalizaron las variables de interés, dando lugar a una primera versión de la guía de observación que incluía de 62 ítems.

Para validar dicha versión del instrumento se aplicó un jueceo de expertos. Se recurrió a un grupo de 8 especialistas en Comunicación que reunieron las siguientes características: haber desarrollado infografías y haber trabajado el diseño de estrategias de comunicación relacionadas con la salud y el gobierno. Mediante un cuestionario, cada juez determinó, según su propio criterio, la relevancia del ítem en función de cada variable propuesta, a partir de la siguiente escala: a) Indispensable, b)

Revista de Comunicación y Salud, 2020, Vol. 10, nº 2, pp. 81-108 
Infografías sobre calidad de vida difundidas por el gobierno de México en el sitio

"Todo sobre el COVID-19"

Útil, pero no indispensable, y c) No indispensable. Igualmente, se agregó un espacio para recibir los comentarios de cada juez sobre cómo mejorar la redacción de cada ítem. Posteriormente, se calculó la razón de validez de contenido de Lawshe - Tristán (2008) para cada ítem, conservándose únicamente aquellos que obtuvieron valores a 0.85, tal y como señala este modelo de validación. Es así como se conservaron de 55 ítems.

Considerando que, la observación se propuso identificar la presencia o ausencia de las características que los autores señalan como parte de cada variable, se codificaron las respuestas como preguntas dicotómicas -0 para ausencia, 1 para presencia-. Luego, se piloteó el instrumento con dos codificadores que realizaron el registro de sus observaciones con la segunda versión del instrumento. Con los valores registrados, se calculó el coeficiente de fiabilidad de Holsti, que refirió un valor de 0.78; este valor tiende al total acuerdo, pues es cercano a 1.

Por último, se dio un tratamiento estadístico descriptivo a los datos que se recopilaron en las observaciones, mediante el programa Excel. De esta forma se obtuvieron gráficos y tablas que concentran los resultados con base en las categorías de cada variable. Es preciso mencionar que, para la construcción y el análisis de las tablas de frecuencia correspondientes a la variable Calidad de Vida, se tomaron como número total de elementos a la cantidad de infografías que incluyeran el ámbito que se menciona. En cambio, para la variable Infografía, el procesamiento englobó al total de los elementos de la muestra.

\section{RESULTADOS}

En este apartado se presentarán los resultados de obtenidos en este estudio. Como punto de partida, se identificó que los infográficos se dirigen a distintos públicos meta. En su mayoría, la información contenida está orientada al público en general -8 de cada 10 infográficos-; aunque se direccionan algunas piezas comunicativas a personal de salud y a otras poblaciones de interés. Esta información se resume en el gráfico 1.



Gráfico 1. Público al que se dirige el infográfico.

Fuente: Elaboración propia con base en los datos obtenidos de la muestra.

Revista de Comunicación y Salud, 2020, Vol. 10, № 2, pp. 81-108 
Infografías sobre calidad de vida difundidas por el gobierno de México en el sitio "Todo sobre el COVID-19"

Asimismo, al observar los infográficos se valoró la congruencia de estos elementos visuales con el emisor y productor -el Gobierno de México- y para los fines que fue creado el sitio, que es la difusión de información de la pandemia. El grafico 2 expone que, aunque todos los infográficos se vincularon a la temática del COVID-19, poco más de $2 / 3$ partes de estas infografías se ciñeron a las características que se visualizan en la campaña de la Jornada Nacional de Sana Distancia. Además, hubo un uso limitado de etiquetas relacionadas con la pandemia. Las etiquetas que más se utilizaron fueron \#QuedateEnCasa, \#SanaDistancia, \#CuidaTuSaludMental, \#EscuchemosPrimero, y \#FrenteALasAdicciones -revise la figura 5 del anexo donde aparece el total de las etiquetas que se identificaron-.

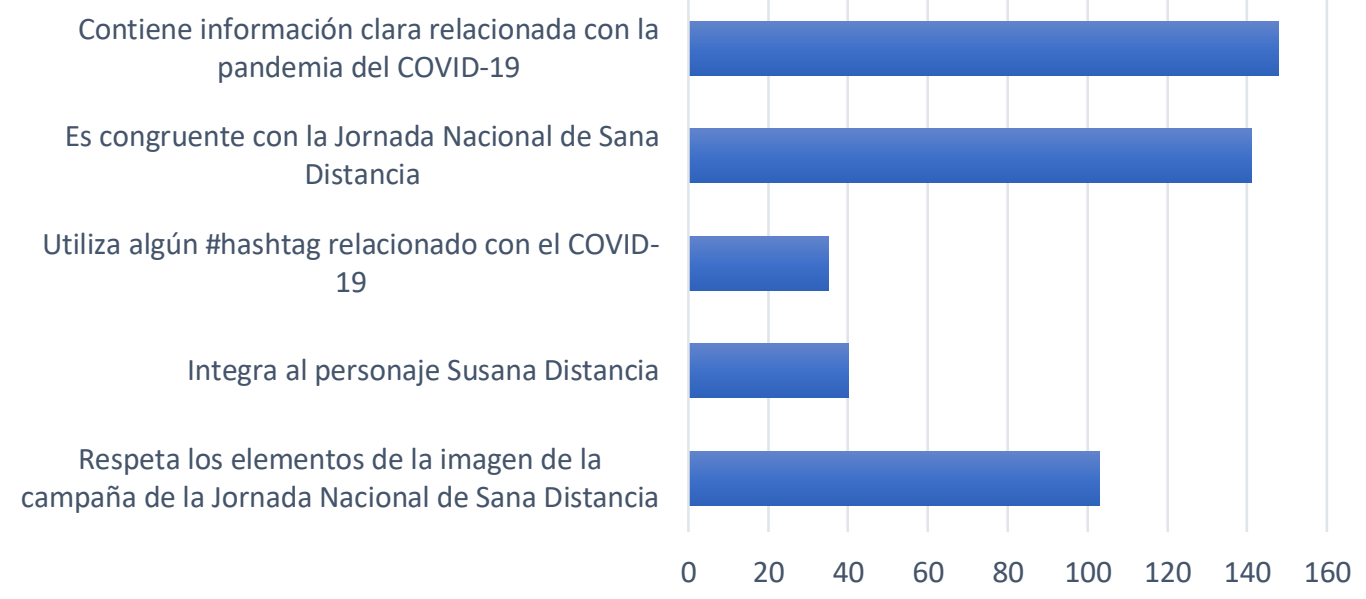

Gráfico 2. Elementos relacionados con el COVID-19 y la Jornada Nacional de Sana Distancia que se identifican en el infográfico.

Fuente: Elaboración propia con base en los datos obtenidos de la muestra.

\subsection{Calidad de vida.}

La Calidad de Vida fue parte de las variables de interés de esta investigación. Se identificó que el ámbito que más se difundió a través de los infográficos fue la Calidad de Vida en Salud. El 40\% de los infográficos incluyen más de 2 ámbitos de la Calidad de Vida. La Calidad de Vida Laboral es la que menos se difunde, apareciendo tan sólo en el $31 \%$ de las infografías -consulte esta información en el gráfico 3-. Es así como se publicaron 83 infográficos en el ámbito social, 93 infografías en el ámbito de la salud y el ámbito laboral se visualiza en 47 infografías. 
Infografías sobre calidad de vida difundidas por el gobierno de México en el sitio "Todo sobre el COVID-19"

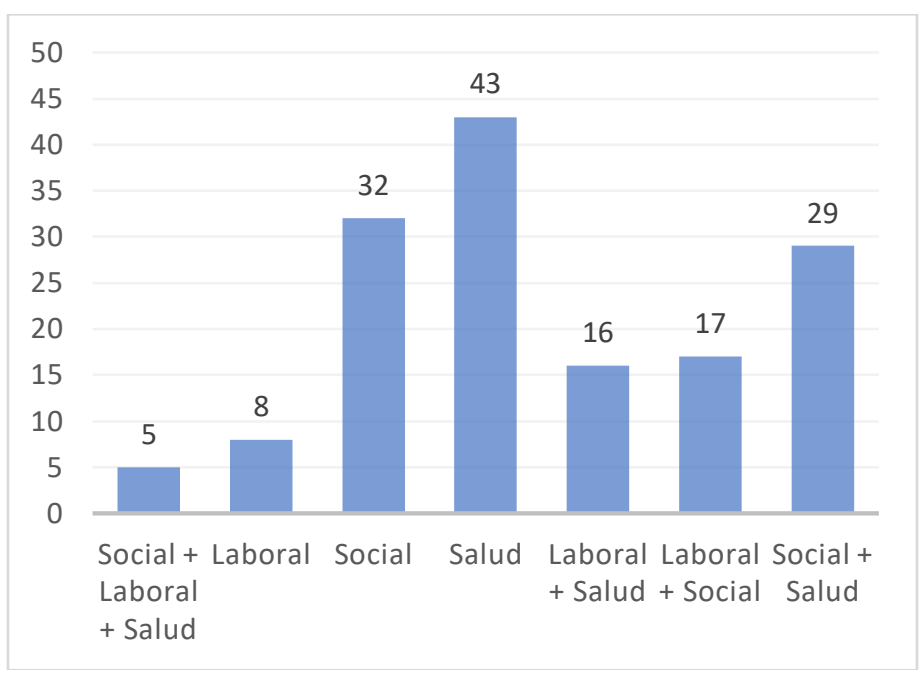

Gráfico 3. Ámbitos de la Calidad de Vida abordada en los infográficos Fuente: Elaboración propia con base en los datos obtenidos de la muestra.

Acerca de la Calidad de Vida en Laboral, la tabla 2 permite observar que los mensajes que se identificaron en torno a esta categoría están vinculados a las medidas de seguridad aplicables para mantenerse seguro en los espacios de trabajo, así como lograr alcanzar los objetivos laborales que tienen los individuos. Es significativo que, tan sólo en el $9 \%$ de los infográficos se habla sobre cómo aplicar estrategias para disminuir el estrés laboral, o de la importancia de tener un empleo para el bien común de la sociedad, con un $13 \%$.

Tabla 2. Presencia de elementos de Calidad de Vida Laboral en las infografías observadas.

\begin{tabular}{|l|r|r|}
\hline & \multicolumn{2}{|c|}{ Presencia } \\
\cline { 2 - 3 } Ítem & Fr. & $\%$ \\
\hline $\begin{array}{l}\text { Expresa cómo lograr satisfacción sobre asuntos laborales considerando la pandemia } \\
\text { vigente }\end{array}$ & 23 & $49 \%$ \\
\hline Describe como alcanzar el rendimiento laboral a partir de la contingencia & 22 & $47 \%$ \\
\hline Promueve la motivación laboral bajo las condiciones actuales & 20 & $43 \%$ \\
\hline $\begin{array}{l}\text { Señala como aplicar medidas de seguridad para salvaguardar su salud en el espacio } \\
\text { laboral/teletrabajo }\end{array}$ & 35 & $74 \%$ \\
\hline $\begin{array}{l}\text { Menciona la importancia de buscar la satisfacción de necesidades afectivas -apoyo } \\
\text { entre colegas, grupos de trabajo, directivos, entre otros- en el ámbito laboral actual }\end{array}$ & 8 & $17 \%$ \\
\hline Contribuye a buscar soluciones para evitar el estrés laboral del trabajo/teletrabajo & 4 & $9 \%$ \\
\hline Explica estrategias para alcanzar sus metas/objetivos en el ámbito laboral & 20 & $43 \%$ \\
\hline Promueve que tener un empleo es favorable para el crecimiento de la comunidad & 6 & $13 \%$ \\
\hline Motiva al individuo para ser más productivo en su trabajo/teletrabajo & 17 & $36 \%$ \\
\hline Señala como evitar contagios en el entorno laboral & 23 & $49 \%$ \\
\hline
\end{tabular}

Fuente: Elaboración propia con base en International Labour Organization (2020), Organización Internacional del Trabajo en América Latina (2020) y los datos recuperados de la muestra. 
Infografías sobre calidad de vida difundidas por el gobierno de México en el sitio "Todo sobre el COVID-19"

Al visualizar la información contenida en el infográfico sobre la categoría Calidad de Vida en Salud, se observa que los infográficos revisados enfatizaron sobre el cuidado de la salud durante el confinamiento, así como la ejecución de buenas prácticas durante este periodo. El elemento que fue menos abordado tiene que ver con la realización de actividades artísticas y culturales como un medio para favorecer la salud del individuo. La tabla 3 concentra todos los ítems observados para este ámbito.

Tabla 3. Presencia de elementos de Calidad de Vida en Salud en las infografías observadas.

\begin{tabular}{|l|r|c|}
\hline \multirow{2}{*}{ Ítem } & Presencia \\
\cline { 2 - 3 } Se expone la importancia del cuidado de la salud durante el confinamiento & Fr. & \multicolumn{1}{|c|}{} \\
\hline Contribuye a buscar soluciones para evitar el estrés en el confinamiento & 70 & $75 \%$ \\
\hline $\begin{array}{l}\text { Motiva al receptor a seguir objetivos de vida, aunque estemos en medio de una } \\
\text { contingencia }\end{array}$ & 31 & $33 \%$ \\
\hline $\begin{array}{l}\text { Presenta prácticas saludables para mantener un buen estado de salud en casa - } \\
\text { alimentación, sueño, hidratación, entre otras-. }\end{array}$ & $24 \%$ \\
\hline $\begin{array}{l}\text { Menciona como aplicar medidas de seguridad para salvaguardar su salud dentro de } \\
\text { casa }\end{array}$ & 58 & $62 \%$ \\
\hline Explica cómo aplicar medidas de seguridad para salvaguardar su salud fuera de casa & 33 & $35 \%$ \\
\hline $\begin{array}{l}\text { Proporciona información al lector para que evalúe su estado de salud considerando la } \\
\text { situación del COVID 19 }\end{array}$ & $48 \%$ \\
\hline $\begin{array}{l}\text { Sensibiliza al lector sobre el cuidado de su cuerpo (funcionamiento físico: ejercicio, } \\
\text { piel, ojos, boca, etc.) }\end{array}$ & 22 & $24 \%$ \\
\hline $\begin{array}{l}\text { Propone realizar actividades artísticas y culturales para contribuir a la salud mental del } \\
\text { individuo }\end{array}$ & 32 & $34 \%$ \\
\hline
\end{tabular}

Fuente: Elaboración propia con base en los datos obtenidos de la muestra.

Por otro lado, se valoraron los mensajes relacionados con la Calidad de Vida Social. Sobre esta categoría es relevante que más del $90 \%$ de los infográficos promovió la importancia de mantener un buen comportamiento de los ciudadanos durante la pandemia. En cambio, la difusión de mensajes relacionados con la igualdad de oportunidades para todos los individuos se efectuó en menor medida en estos infográficos -revise la tabla 4 para precisar sobre estos resultados-.

Tabla 4. Presencia de elementos de Calidad de Vida Social en las infografías observadas.

\begin{tabular}{|l|r|c|}
\hline \multirow{2}{*}{ Ítem } & Presencia \\
\cline { 2 - 3 } $\begin{array}{l}\text { Mejora la percepción del lector ante las fases de la contingencia que se vive en su } \\
\text { entorno }\end{array}$ & Fr. \\
\hline $\begin{array}{l}\text { Provoca una percepción de igualdad de oportunidades para todos los habitantes del } \\
\text { país }\end{array}$ & 35 & $42 \%$ \\
\hline $\begin{array}{l}\text { Sensibiliza al lector sobre la importancia de mantener la sana distancia con las personas } \\
\text { que interactúa fuera de su hogar }\end{array}$ & $37 \%$ \\
\hline $\begin{array}{l}\text { Enfatiza sobre el respeto por los demás a través de las buenas prácticas en espacios } \\
\text { públicos }\end{array}$ & 38 & $46 \%$ \\
\hline
\end{tabular}

Revista de Comunicación y Salud, 2020, Vol. 10, no 2, pp. 81-108 
Infografías sobre calidad de vida difundidas por el gobierno de México en el sitio "Todo sobre el COVID-19"

\begin{tabular}{|l|r|r|}
\hline Promueve la adopción de una actitud solidaria para mantener la salud de la comunidad. & 56 & $67 \%$ \\
\hline Impulsa a que el receptor contribuya a un clima social armónico a pesar de la pandemia & 50 & $60 \%$ \\
\hline $\begin{array}{l}\text { Subraya la importancia de conservar un fuerte sistema de valores en la comunidad para } \\
\text { incidir positivamente en la salud de todos }\end{array}$ & 42 & $51 \%$ \\
\hline $\begin{array}{l}\text { Promueve mensajes que estimulan al buen comportamiento de los individuos durante la } \\
\text { pandemia }\end{array}$ & 80 & $96 \%$ \\
\hline Sensibiliza al lector sobre el cuidado de las personas con las que vive. & 39 & $83 \%$ \\
\hline
\end{tabular}

Fuente: Elaboración propia con base en los datos obtenidos de la muestra.

\subsection{Infografía.}

Como parte de la variable infografía se determinaron algunas categorías de interés. Con respecto a la categoría Mensaje que proyectan los infográficos observados, se detectó que en más del $95 \%$ de los casos, las infografías que se muestrearon presentan mensajes concisos, comprensibles, con lo más relevante del tema y que no dan pie a información que genere especulación sobre la pandemia -revise el gráfico 4 para profundizar en estos resultados-. Cabe señalar que los gráficos 4, 5 y 6 se construyeron bajo la misma lógica, esto es, muestran el número de infografías que si presentaron los ítems propuestos correspondientes a la categoría que se señala.

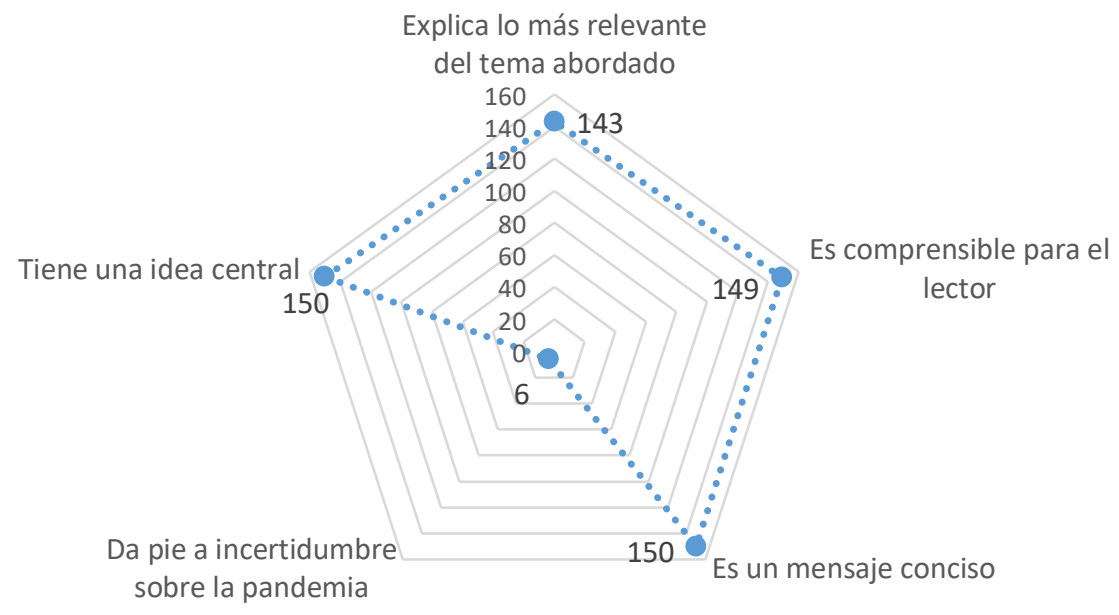

Gráfico 4. Mensaje que proyectan los infográficos.

Fuente: Elaboración propia con base en los datos obtenidos de la muestra.

La función que desarrollo el infográfico también fue valorada en esta investigación. Como se aprecia en el gráfico 5 , la función que más se cubrió por los infográficos observados es la de resumir la información relacionada con la pandemia. En contraste, la difusión de información que otras agencias u organismos internacionales han generado con antelación es la función que menos se identificó en las infografías que se incluyeron a la muestra. 
Infografías sobre calidad de vida difundidas por el gobierno de México en el sitio "Todo sobre el COVID-19"

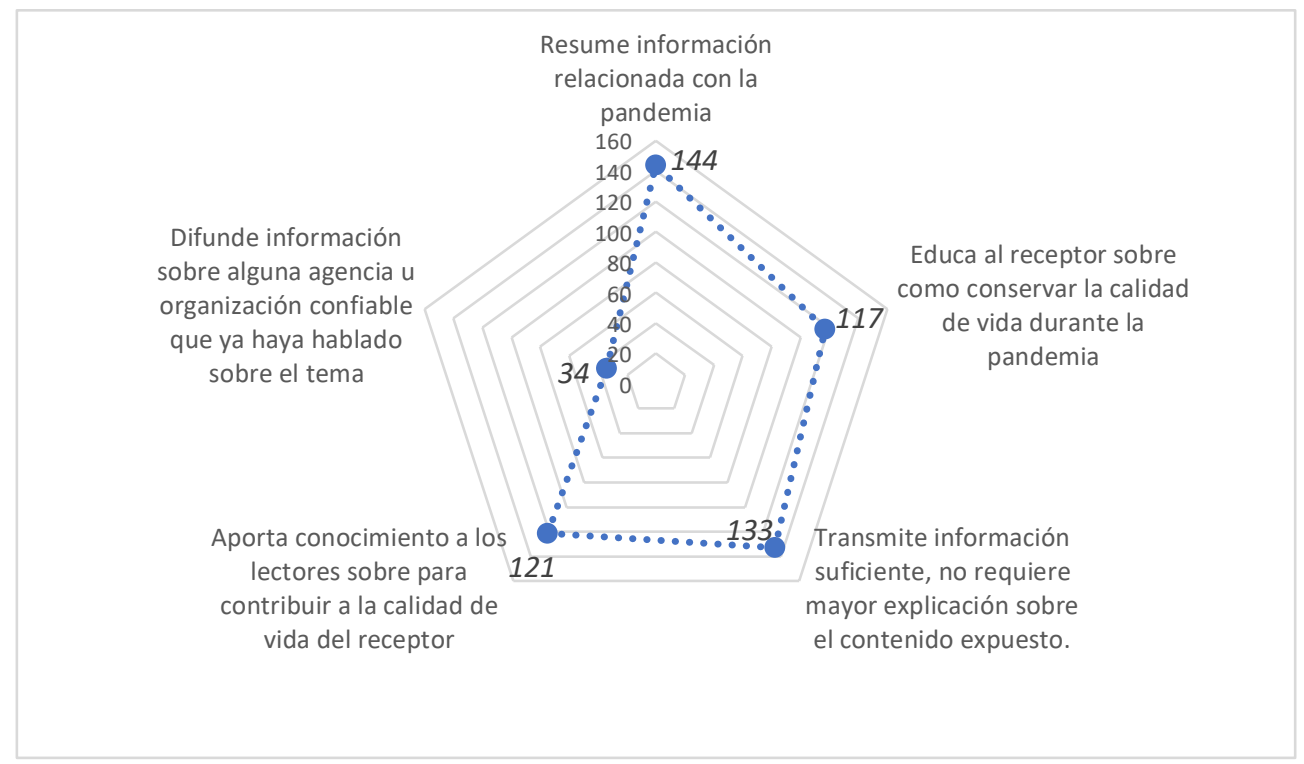

Gráfico 5. Función que cumplen los infográficos observados

Fuente: Elaboración propia con base en los datos obtenidos de la muestra.

Otra categoría de interés fueron los elementos que se observan en la estructura de la infografía. De acuerdo con los datos recuperados, se aprecia que la mayoría de los infográficos incluyen un título atractivo y tienen un diseño que favorece su lectura, combinando adecuadamente el texto y las imágenes implementadas. En cambio, se detectó que poco más del $50 \%$ de los infográficos no integran una fuente de información que sustente los datos expuestos en estas piezas comunicativas. Estos datos aparecen sintetizados en el gráfico 6.

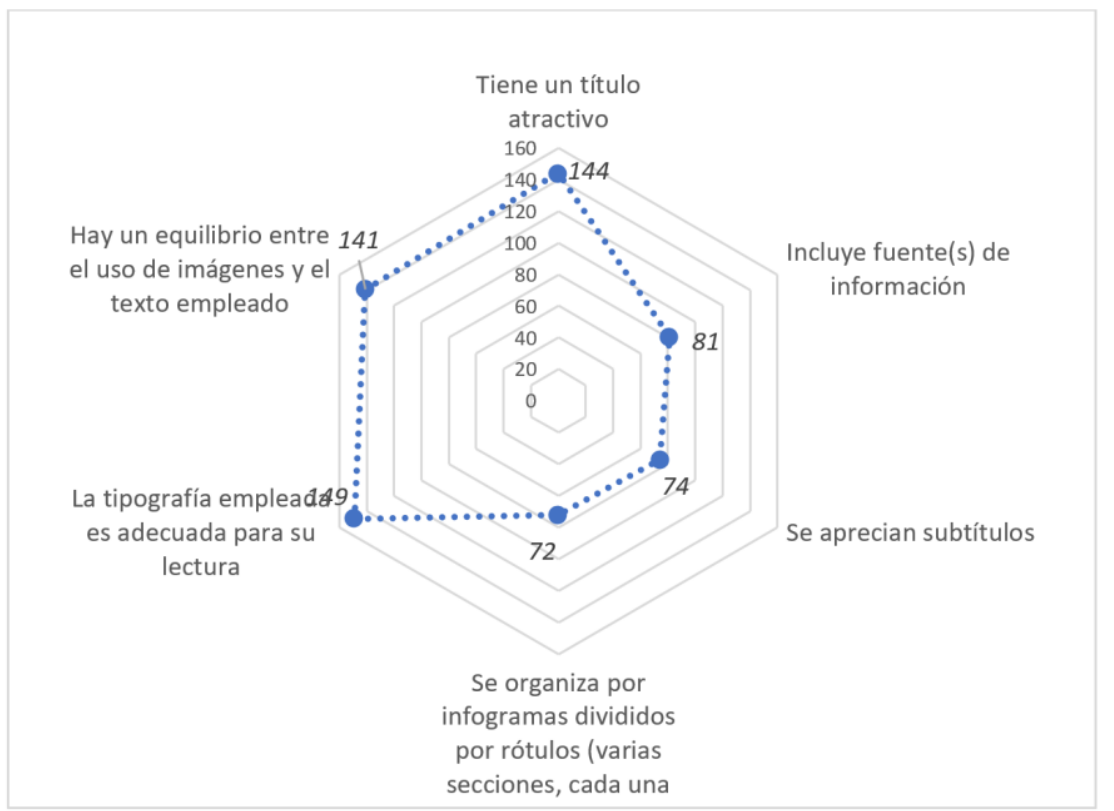

Gráfico 6. Elementos identificados en la estructura de la Infografía.

Fuente: Elaboración propia con base en los datos obtenidos de la muestra.

Revista de Comunicación y Salud, 2020, Vol. 10, no 2, pp. 81-108 
De los infográficos que sí reportaron fuentes de información destaca que casi la mitad de estos productos comunicativos se sustentan en información estadística que el propio Gobierno de México ha generado desde los distintos departamentos que lo constituyen -como son Secretarías, institutos, comisiones, entre otros-. Las fuentes de información que se mencionan en las piezas comunicativas se visualizan en gráfico 7.

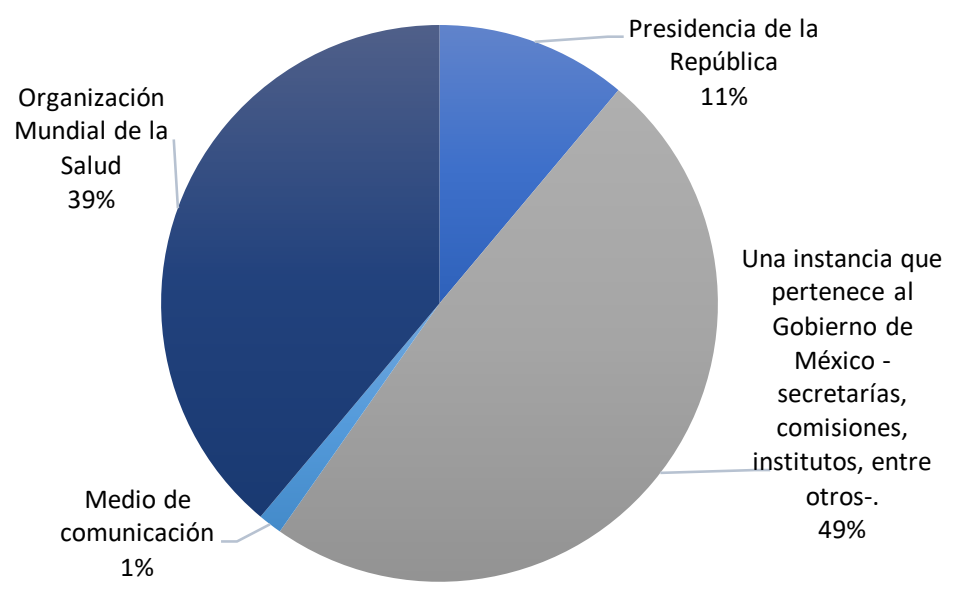

Gráfico 7. Tipo de fuentes de información mencionadas en los infográficos observados Fuente: Elaboración propia con base en los datos obtenidos de la muestra.

\section{DISCUSIÓN}

Una vez que se han procesado los datos, en este apartado se presenta la discusión de los resultados obtenidos. En primera instancia, resulta significativo que por lo menos uno de los ámbitos de la Calidad de Vida es mencionado en todos los infográficos que se observaron. Esto atiende a la definición del concepto de Salas y Garzón (2013), pues se trata de mensajes que abordan algún aspecto desarrollo humano, las relaciones laborales y con el entorno que tienen los individuos. Dichos mensajes se orientan a apoyar al receptor sobre como sobrellevar o conservar su Calidad de Vida durante el confinamiento. Con esto, se atiende el objetivo general de esta investigación.

Parece relevante mencionar que los contenidos que se presentan en los infográficos, también se ciñen a la campaña de la JSND, y al mismo tiempo contribuye a la consolidación de la imagen institucional de la actual gestión (Márquez, Molina y Mejía, 2017), al difundir mensajes que apoyen a sus públicos a tener experiencias positivas en torno a la contingencia, y que al mismo tiempo denotan el rol de acompañamiento que desempeña el Estado Mexicano.

Atendiendo a los mensajes de los infográficos que se vinculan a los ámbitos de las Calidad de Vida -el objetivo específico A de esta investigación- sobresalen algunos hallazgos. En el ámbito de la Calidad de Vida laboral, la información proporcionada trata de orientar a los lectores, como lo subrayan Alves, Cirera y Carlos (2013), sobre como continuar realizando su trabajo y seguir siendo productivos, aun cuando se encuentre 
Infografías sobre calidad de vida difundidas por el gobierno de México en el sitio "Todo sobre el COVID-19"

en confinamiento -trabajo remoto-; o bien, tengan que asistir a un espacio laboral fuera de casa (Internacional Labour Organization, 2020). A pesar de ello, se identificaron pocos mensajes que se asociaran al control de emociones, inteligencia emocional 0 manejo de estrés; que son elementos que condicionan a la Calidad de Vida Laboral (Nanjundeswaraswamy y Sandhya, 2016; Organización Internacional del Trabajo en América Latina, 2020). Lo que representa un tema pendiente por atender en este tipo de piezas de comunicación.

Sobre el ámbito de la salud, hay una intención en gran parte de los infográficos, de que los individuos valoren la adopción de prácticas saludables para el cuidado de sí mismos y de quienes los rodean como mencionan Lopera (2020) y Cáceres-Manrique, Parra-Prada y Pico-Espinosa (2018). No obstante, hace falta incrementar los mensajes que contengan una visión de largo plazo, vinculada a las metas de vida y la motivación intrínseca del individuo, como lo subrayan Sanjuán y Ávila (2016), en aras de que se incentive la salud física y mental de los receptores. En este caso, es conveniente que el Estado Mexicano reenfoque sus mensajes pues si bien este es el ámbito de Calidad de Vida más abordado, no abarca con la misma intensidad algunos de los elementos vinculados a la salud mental.

La Calidad de Vida relacionada con el ámbito social, se visualizan mensajes que buscan concientizar al individuo sobre la importancia de realizar acciones individuales que afecten positivamente en el colectivo. Es decir, se enfatiza sobre el impacto que tiene el seguimiento de medidas de salud, para evitar que la enfermedad se propague. Esto atiende a lo postulado por Danilova, Kovrigina y Khuziakhmetov (2020), que enfatizan sobre la importancia de honrar los valores y normas de la comunidad, así como fortalecer la confianza y la solidaridad entre los integrantes de una sociedad.

Hay que agregar que, estos mensajes se ven reforzados con el uso de etiquetas que se insertaron en los infográficos. Estas etiquetas se enfocan en las conductas deseables de los individuos durante la contingencia; pero no se centran únicamente en la pandemia, ya que incluyen comportamientos del día a día para la sana convivencia. Algunas de estas etiquetas son \#QuedateEnCasa y \#SanaDistancia, que se complementan con \#EscuchemosPrimero y \#Sin Discriminación.

Adicionalmente, como parte de los objetivos de que se propusieron para esta investigación, se delimitó el contenido que incluyen los infográficos sobre el COVID-19 que fueron socializados por el estado mexicano -objetivo específico B-. Tomando en cuenta los mensajes que se emitieron a las infografías, casi en su totalidad cumplen con las características que Madurga (2016) y Sanz y Castejón (2018) proponen, al ser piezas comunicativas sintéticas, comprensibles, de fácil lectura, que atienden a la necesidad de información que tiene el lector.

También, se evaluó la función que cubrieron los infográficos de Calidad de Vida muestreados. Hay una tendencia por presentar información resumida sobre la pandemia (Madurga, 2016); así como la intención de educar al receptor sobre la temática que tratan (Saroja, 2020). Pese a esto, es imperativo que esta funcionalidad se 
Infografías sobre calidad de vida difundidas por el gobierno de México en el sitio

"Todo sobre el COVID-19"

vea reflejada en todas las piezas comunicativas que se publican, dada la representatividad y la función que tiene el emisor, en este caso, el Gobierno de México.

A la par, se definieron los elementos identificados que la estructura de las infografías observadas tiene. Es significativos que el diseño es atractivo, con un manejo adecuado de colores, imágenes y tipografía. En cuanto al sustento de los datos que se exponen, casi la mitad de los productos comunicativos que cuentan con una referencia, se respaldan en información que ha generado el propio Estado Mexicano.

Al mismo tiempo, hay una gran proporción de unidades informativas que no cuentan con fuentes de información. Esta es un área de oportunidad que no debe ser tomada a la ligera, ya que este tipo de omisiones puede conllevar a que se cuestione la veracidad y la calidad de los contenidos expuestos. Siricharoen y Siricharoen (2015) ya han remarcado lo importante que es proyectar en un infográfico un balance entre estética y ética con respecto a la credibilidad de los datos expuestos.

\section{CONCLUSIONES}

Considerando los hallazgos que arrojo este proceso de investigación, los datos procesados respaldan la idea expuesta por Català Domínguez (2018) y Muñoz del Bosque (2017) en el sentido de que los infográficos son una buena opción para difundir información relacionada con la Calidad de Vida. Para que esta práctica sea aún más efectiva, habrá que atender a la evaluación previa, con alto nivel de rigor (Arum, 2017) para asegurar la calidad de lo que se expone a los receptores.

Esta investigación se orientó a ubicar los mensajes vinculados con la Calidad de Vida durante lo que va de la contingencia en México. No obstante, es importante que para entender el efecto los mensajes transmitidos a las audiencias, se realicen futuras investigaciones en donde el receptor evalúe el contenido del infográfico y emita una retroalimentación al mismo. Igualmente, desde los públicos, se puede identificar qué otros mensajes o qué tipo de información requieren o necesitan con mayor profundidad para continuar promoviendo su Calidad de Vida durante esta etapa de confinamiento que se está dando.

Por otro lado, este trabajo se enfocó en identificar la presencia o ausencia de características propias de los infográficos, así como de las características de dimensiones de la Calidad de Vida, en función de lo que los autores revisados han señalado. Por ello, queda como un área de oportunidad, que se realicen investigaciones que analicen el contenido desde un punto de vista semiótico.

Finalmente, los productos comunicativos visuales, son cada vez más consultados por los receptores. Por lo que es preciso continuar con la valoración y socialización de buenas prácticas en la construcción de infográficos sobre temas de salud. Esto es una prioridad, considerando que, los niveles de alfabetización informacional de los usuarios de internet aun no son suficientes para la evaluación de los contenidos que consumen 
Infografías sobre calidad de vida difundidas por el gobierno de México en el sitio

"Todo sobre el COVID-19"

diariamente en los ambientes virtuales. Esta es entonces una tarea más para el campo de la Comunicación para la Salud.

\section{REFERENCIAS}

Abaleron, C. A. (1998), Calidad de vida como categoría epistemológica. AREA. Agenda de reflexión en arquitectura, diseño y urbanismo, 6, 3-15. Recuperado de https://area.fadu.uba.ar/wp-content/uploads/AREA06/06 abaleron.pdf

Alves C., D., Cirera O., Y., Carlos G., A. (2013). Vida con calidad y calidad de vida en el trabajo. Invenio, 16(30), 145-163. Recuperado de https://dialnet.unirioja.es/descarga/articulo/4237669.pdf

Ardila, R. (2003). Calidad de vida: una definición integradora. Revista Latinoamericana de Psicología, 35(2), 161-164. Recuperado de https://www.redalyc.org/pdf/805/80535203.pdf

Angulo Hurtado, A. M., Ramírez Quintana, A. S. (2016). Relación entre la calidad de vida en salud y la carga física en cuidadores de personas con enfermedad de Alzheimer. Revista Colombiana de Salud Ocupacional, 6(1). 20-26. doi: $\underline{10.18041 / 2322-634 X / \text { rcso.1.2016.4887 }}$

Arum, N. S. (2017). Infographic: Not Just a Beautiful Visualization. Obtenido de https://www.academia.edu/31903865/Infographic Not Just a Beautiful Visualisation

Baldi, G. (2010). Percepción de la calidad de vida en una muestra de individuos residentes en la región de Cuyo, Argentina. Fundamentos en Humanidades, 11(22), 177-192. Recuperado de http://fundamentos.unsl.edu.ar/pdf/articulo-22-177.pdf

Buljan, I., Malički, M., Wager, E., Puljak, L., Hren, D., Kellie, F., West, H., Alfirević, Ž., \& Marušić, A. (2018). No difference in knowledge obtained from infographic or plain language summary of a Cochrane systematic review: Three randomized controlled trials. Journal of clinical epidemiology, 97, 86-94. doi: 10.1016/j.jclinepi.2017.12.003

Cáceres-Manrique, F. M., Parra-Prada, L. M. y Pico-Espinosa, O. J. (2018). Calidad de vida relacionada con la salud en población general de Bucaramanga, Colombia. Revista Salud Pública, 20(2), 147-154. doi: 10.15446/rsap.v20n2.43391

Català Domínguez, J. (2018). Infografía: cambio de escenario. En Nuevas narrativas visuales. José Luis Valero Sancho (Dir). Cuadernos Artesanos de Comunicación, 150. La Laguna Tenerife: Latina, pp. 137-164. Disponible en http://www.cuadernosartesanos.org/2018/cac150.pdf

Cox, R., De Goeij, P. (2020). Infographics and Financial Decisions. Nueva Zelanda: Netspart Industry Series

Revista de Comunicación y Salud, 2020, Vol. 10, no 2, pp. 81-108 
Infografías sobre calidad de vida difundidas por el gobierno de México en el sitio "Todo sobre el COVID-19"

Danilova, E. P., Kovrigina, T. A., Khuziakhmetov, R. R. (2020, Marzo 18-19). Management of social development of the Russian Arctic. [Sesión de conferencia]. 5th International Conference Arctic: History and Modernity, San Petersburgo, Rusia.

El Universal. Las otras vidas de Susana Distancia. Obtenido de https://www.eluniversal.com.mx/nacion/susana-distancia-la-heroina-de-la-salud-y-delempoderamiento-de-la-mujer

García Soto, S. (2019). Internet y redes, prioridad en comunicación de la 4T. Obtenido de https://tinyurl.com/yx8gc8px

Gobierno de México. (2020). Todo sobre el COVID-19. Obtenido de https://coronavirus.gob.mx/

González Celis, A. (2005). ¿Cómo mejorar la calidad de vida el bienestar subjetivo de los ancianos? En L. Garduño, B. Salinas \& M. Rojas, Calidad de vida y bienestar subjetivo en México. (259-294). México: Plaza y Valdez.

Google Trends. (2020a). Infografía del coronavirus. Obtenido de https://trends.google.es/trends/explore?gprop=images\&q=infograf\%C3\%ADa\%20del \%20coronavirus

Google Trends. (2020b). coronavirus.gob.mx. Obtenido de https://trends.google.es/trends/explore?gprop=images\&q=coronavirus.gob.mx

Instituto Nacional de Estadística, Geografía e Informática. (2015). México en cifras. Obtenido de https://www.inegi.org.mx/app/areasgeograficas/?ag=00

International Labour Organization. (2020). COVID-19: Guidance for labour statistics data collection. Obtenido de https://tinyurl.com/yxbc4l4k

Lee, M. A. (2015). The Effects of Social Quality on Suicide Ideation of Korean Elderly. Journal of Digital Convergence. 13(3), 271-281. doi: 10.14400/JDC.2015.13.3.271

Leva, G. (2005). Indicadores de Calidad de Vida Urbana. Quilmes, Argentina: Universidad de Quilmes - Habitat Metrópolis. Disponible en http://hm.unq.edu.ar/archivos hm/GL ICVU.pdf

Lindenboim, J., Ainstein, L., Liberali, A. M., Acciarri, S., Grané, M., López Imizcoz, C., Pohl, V., Sfich, V. (2000, septiembre 13-15). Calidad de vida urbana: Una discusión conceptual. [Sesión de conferencia]. II Jornadas de Geografía de la UNLP. La Plata, Argentina.

Lopera, J. P. (2020). Calidad de vida relacionada con la salud: exclusión de la subjetividad. Ciênc. saúde coletiva, 25(2), 693-702. doi: 10.1590/1413$\underline{81232020252.16382017}$ 
Infografías sobre calidad de vida difundidas por el gobierno de México en el sitio

"Todo sobre el COVID-19"

Martínez Gamarra, M., Ros Mar, R. (2010). De la calidad de la vida laboral a los riesgos Psicosociales evaluación de la calidad de vida laboral. Acciones e investigaciones sociales, 28, 5-55. doi: 10.26754/ojs ais/ais.201028480

Márquez, J., Molina, O. y Mejía, L. (2017). La gestión de comunicación del municipio de Montecristi y su influencia en la imagen institucional. ReHuSo Revista de Ciencias Humanísticas y Sociales, 2(1), 34-50. Recuperado de https://revistas.utm.edu.ec/index.php/Rehuso/article/view/496/740

Madurga, J. (2016). Ventajas y Desventajas de las infografías. NeoAttack: https://neoattack.com/ventajas-y-desventajas-de-crear-una-infografia-en-tus-post/

Nanjundeswaraswamy, T. S., Sandhya, M. N. (2016). Quality of Work Life Components: A Literature Review. The International Journal of Indian Psychology. 4(75), 12-36

Nielsen, H. C. (2017). Infographics at WHO/Europe. European Journal of Public Health, 27(Supplement 3), 8-10.

Karimi, M., Brazier, J. (2016). Health, Health-Related Quality of Life, and Quality of Life: What is the Difference? PharmacoEconomics, 34(7), 645-649. doi: 10.1007/s40273$\underline{016-0389-9}$

Organización Internacional del Trabajo en América Latina. (2020). Seguridad y salud en el trabajo frente a la pandemia. Obtenido de https://tinyurl.com/yxz49ftt

Organización Mundial de la Salud. (2002). Programa Envejecimiento y Ciclo Vital. Envejecimiento activo: un marco político. Revista Española de Geriatría y Gerontología, 37(S2), 74- 105. https://www.elsevier.es/es-revista-revista-espanolageriatria-gerontologia-124-articulo-envejecimiento-activo-un-marco-politico-13035694

Patel, Z., Patel, C., Oreper, J., Patel, H., Sajedeen, A. (2020). Healthcare Professionals' Perceptions of infographics within medical information response letters. Therapeutic Innovation \& Regulatory Science (TIRS), 54(4), 1-20. doi: 10.1007/s43441-020$\underline{00164-w}$

Patrick, D. L., Erickson, P. (1993). Health Status and Health Policy: Allocating Resources to Health Care. Nueva York, Estados Unidos de América: Oxford University Press. http://hdl.handle.net/10822/860706

Ponce, A., Rangone, C., Funes, M. (2015, octubre 29-31). Relato de Experiencia: Diseño de infografías como estrategia de enseñanza en educación para la salud en ciencias naturales y su didáctica en profesorados para la educación primaria de la provincia de Córdoba. [Sesión de conferencia]. VIII Jornadas Nacionales y $1^{\circ}$ Congreso Internacional sobre la Formación del Profesorado, Mar del Plata, Argentina. 
Infografías sobre calidad de vida difundidas por el gobierno de México en el sitio "Todo sobre el COVID-19"

Ruvalcaba Romero, N., Salazar Estrada, J. G., Fernández Berrocal, P. (2012). Indicadores sociales, condiciones de vida y calidad de vida en jóvenes mexicanos. Revista Iberoamericana de psicología: Ciencia y tecnología, 5(1), 71-80. Obtenido de https://reviberopsicologia.ibero.edu.co/article/view/rip.5107/205

Rivera Alvarado, A. C. (2020). La COVID-19 y las desigualdades sociales. Pensar la Pandemia. Observatorio Social del Coronavirus, 1-3.

Rivera-Salas, P.E. (2019). Infografías de salud publicadas por organizaciones y autoridades sanitarias en la red social Pinterest. Revista de Investigación en Tecnología de la Información, 7(13), 92-100. Obtenido de https://www.riti.es/ojs2018/inicio/index.php/riti/article/view/155

Robles-Espinoza, A.I., Rubio-Jurado, B., De la Rosa-Galván, E.V., Nava-Zavala, A.H. (2016). Generalidades y conceptos de calidad de vida en relación con los cuidados de salud. El Residente, 11(3), 120-125. Obtenido de https://www.medigraphic.com/cgi-bin/new/resumen.cgi?IDARTICULO=68589

Roney, C., Menjívar, E., Morales, H. (2015). Elaboración de infografías: hacia el desarrollo de competencias del siglo XXI. Diá-Logos, 15, 23-37. doi: $\underline{10.5377 / \text { dialogos.v0i15.2207 }}$

Salas, C. y Garzón, M. O. (2013). La noción de calidad de vida y su medición. CES Salud Pública, 4(1), 36-46.

Salazar, J.E., Pando, M., Arana, C., Heredia, D. E. (2005). Calidad de vida: hacia la formación del concepto. Mediagraphic Artemisa en línea, 7(3), 161-165. Obtenido de https://www.medigraphic.com/pdfs/invsal/isg-2005/isg053d.pdf

Sanjuán, P., Ávila, M. (2016). Afrontamiento y motivación como predictores del bienestar subjetivo y psicológico. Revista de Psicopatología y Psicología Clínica, (21), 1-10. Obtenido de https://www. aepcp.net/arc/01 2016 n1.pdf

Sanz, M., Castejón, R. (2018). Infografías en las ciencias de la salud: aplicación al cuidado domiciliario. Hosp Domic. 2(2), 67-78. doi: 10.22585/hospdomic.v2i2.44

Saroja, M. (2020). Infographics -visual graphic information knowledge. En C. Thanavathi (Eds.). Social Media in Teaching and Learning (89-98). ESN Publications.

Segurado Torres, A. y Agulló Tomás, E. (2002) Calidad de vida laboral: hacia un enfoque integrador desde la Psicología Social. Revista Psicothema, 14(4), 828-836. Recuperado de http://www.psicothema.com/psicothema.asp?id=806

Shumaker, S. A., Naughton, M. J. (1995). The international assessment of healthrelated quality of life: a theoretical perspective. En Shumaker, S.A., Berzon, R. A., Eds. The International Assessment of Health-related quality of life. Theory, Translation, Measurement and Analysis. New York: Rapid Communication, pp. 3-10. 
Infografías sobre calidad de vida difundidas por el gobierno de México en el sitio "Todo sobre el COVID-19"

Siricharoen, W.V., Siricharoen, N. (2015, Mayo 12-15). How infographic should be evaluated? [Sesión de conferencia]. 7th International Conference on Information Technology (ICIT 2015), Aman, Jordan.

Srivastava, y Kapur, (2014). A Study on Quality of Work Life: Key Elements \& It's Implications. IOSR Journal of Business and Management. 16(1), 54-59. Recuperado de http://www.iosriournals.org/iosr-jbm/papers/Vol16-issue3/Version-1/H016315459.pdf

Swany, D. R, Nanjundeswaraswamy, T.S. y Rashmi, S. (2015). Quality of Work Life: Scale Development and Validation. International Journal of Caring Sciences. 8(2), 281-300.

Recuperado

http://www.internationaljournalofcaringsciences.org/docs/6 swamy.pdf

Tristán, A. (2008). Modificación al modelo de Lawshe para el dictamen cuantitativo de la validez de contenido de un instrumento objetivo. Avances de Medición, 6, 37-48. Disponible en http://www.humanas.unal.edu.co/psicometria/files/8413/8574/6036/Articulo4 Indice d e validez de contenido 37-48.pdf

Tomlinson, M., Walker, A., Foster, L. (2016). Social Quality and Work: What Impact Does Low Pay Have on Social Quality? Journal of Social Policy, 45, 345-371. doi: 10.1017/S0047279415000732

Wu, A. W. (2000). Quality-of-life assessment in clinical research: application in diverse populations. Medical Care, 38(9 Suppl), II130-II135.

\section{AUTORA}

\section{Paola Eunice Rivera Salas}

Doctora en Educación (UVHM). Profesora Investigadora de la Facultad de Ciencias de la Comunicación de la Benemérita Universidad Autónoma de Puebla (BUAP), México. Tiene la distinción de Candidata a Investigadora 2019-2021 (SNI). Recibió la Mención Honorífica en el 1er. Premio a la Innovación Educativa en la Docencia 2017, por el Instituto Politécnico Nacional. Su línea de investigación individual es "Educación, Comunicación y TIC". Contribuye también a la línea "Comunicación Responsable en organizaciones, profesiones y medios digitales", que es el eje de investigación del su Grupo de Investigación en "Comunicación Responsable". Es autora y coautora de más de una docena de libros, artículos de investigación y capítulos de libro relacionados con sus líneas de investigación en editoriales de reconocido prestigio.

Orcid ID: https://orcid.org/0000-0002-8050-3585

Google Scholar: https://scholar.google.com/citations?user=se71DCQAAAAJ\&hl=es 
Infografías sobre calidad de vida difundidas por el gobierno de México en el sitio "Todo sobre el COVID-19"

\section{Anexo}

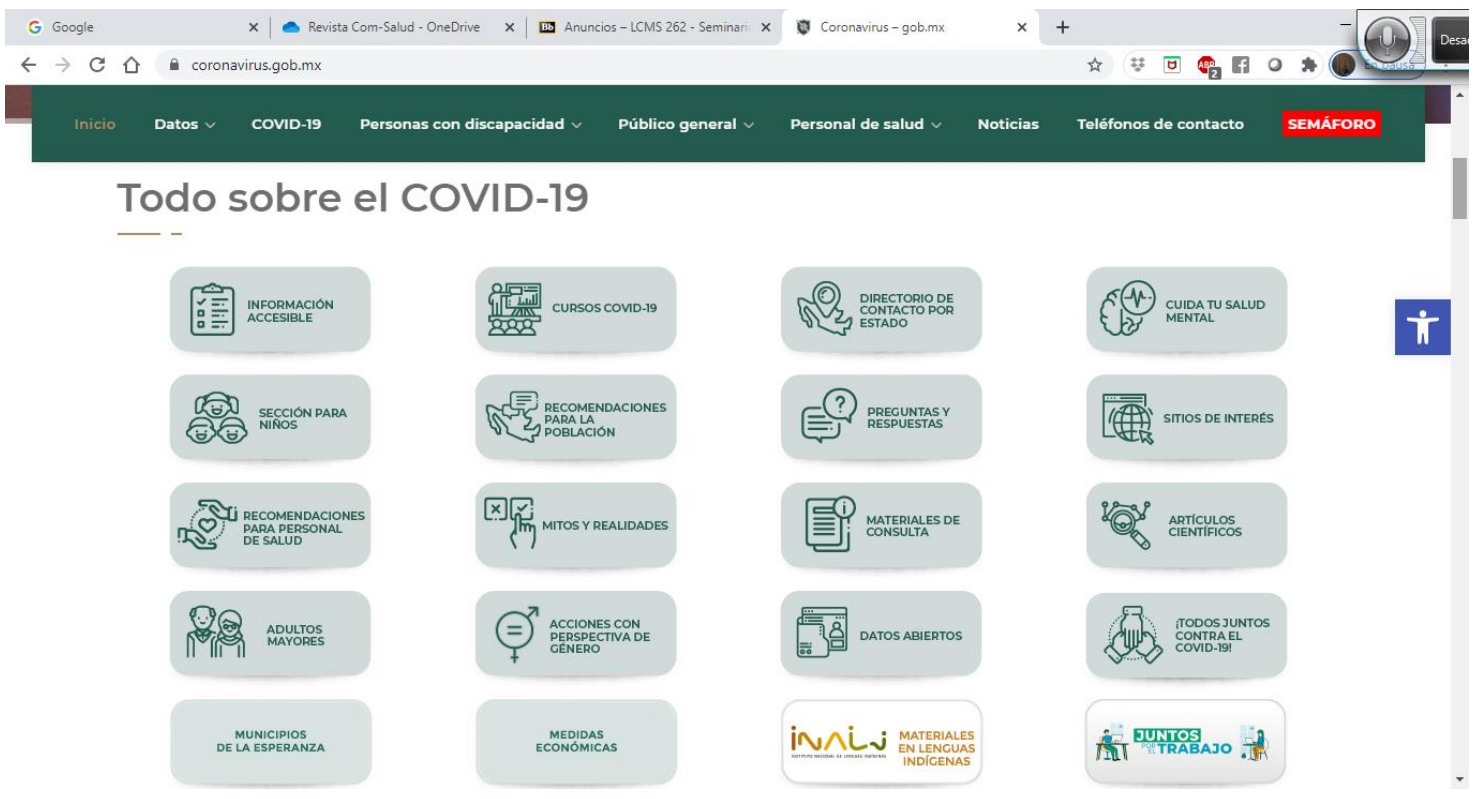

Figura 3. Distribución de los contenidos en la página "Todo sobre el COVID-19" Fuente: Gobierno de México (2020)

\begin{tabular}{|c|c|c|c|c|c|}
\hline \multirow{2}{*}{$\begin{array}{l}\text { Variable de } \\
\text { interés }\end{array}$} & \multirow[b]{2}{*}{ Términos para la búsqueda } & \multicolumn{4}{|c|}{ Bases de Información } \\
\hline & & EBSCO & $\begin{array}{l}\text { Google } \\
\text { Schoolar } \\
\end{array}$ & Dialnet & Scielo \\
\hline \multirow{9}{*}{ Calidad de vida } & calidad de vida & $\mathrm{x}$ & $\mathrm{x}$ & $\mathrm{x}$ & $\mathrm{x}$ \\
\hline & calidad de vida and SARCoV-2 or coronavirus & $\mathrm{x}$ & $\mathrm{x}$ & $\mathrm{x}$ & $\mathrm{x}$ \\
\hline & calidad de vida and trabajo or laboral & $\mathrm{x}$ & $\mathrm{x}$ & $\mathrm{x}$ & $\mathrm{x}$ \\
\hline & calidad de vida and salud & $\mathrm{x}$ & $\mathrm{x}$ & $\mathrm{x}$ & $\mathrm{x}$ \\
\hline & quality life & $\mathrm{x}$ & $\mathrm{x}$ & & \\
\hline & quality life and pandemia & $\mathrm{x}$ & $\mathrm{x}$ & & \\
\hline & quality life and labor or work & $\mathrm{x}$ & $\mathrm{x}$ & & \\
\hline & quality life and health & $\mathrm{x}$ & $\mathrm{x}$ & & \\
\hline & quality life and social & $\mathrm{x}$ & $\mathrm{x}$ & & \\
\hline \multirow{9}{*}{ Infografía } & infografía or infográfico and calidad de vida & $\mathrm{x}$ & $\mathrm{x}$ & $\mathrm{x}$ & $\mathrm{x}$ \\
\hline & infográfico or infografía and calidad de vida and social & $\mathrm{x}$ & $\mathrm{x}$ & $\mathrm{x}$ & $\mathrm{x}$ \\
\hline & infográfico or infografía and calidad de vida and laboral & $\mathrm{x}$ & $\mathrm{x}$ & $\mathrm{x}$ & $\mathrm{x}$ \\
\hline & infográfico or infografía and calidad de vida and salud & $\mathrm{x}$ & $\mathrm{x}$ & $\mathrm{x}$ & $\mathrm{x}$ \\
\hline & infographics and quality life & $\mathrm{x}$ & $\mathrm{x}$ & & \\
\hline & infographics and social and quality life & $\mathrm{x}$ & $\mathrm{x}$ & & \\
\hline & infographics and labour or labour and quality life & $\mathrm{x}$ & $\mathrm{x}$ & & \\
\hline & infographics and health and quality life & $\mathrm{x}$ & $\mathrm{x}$ & & \\
\hline & infographics and coronavirus or SARCoV-2 & $\mathrm{x}$ & $\mathrm{x}$ & & \\
\hline
\end{tabular}

Figura 4. Términos para la búsqueda

Fuente: Elaboración propia. 
Infografías sobre calidad de vida difundidas por el gobierno de México en el sitio "Todo sobre el COVID-19"

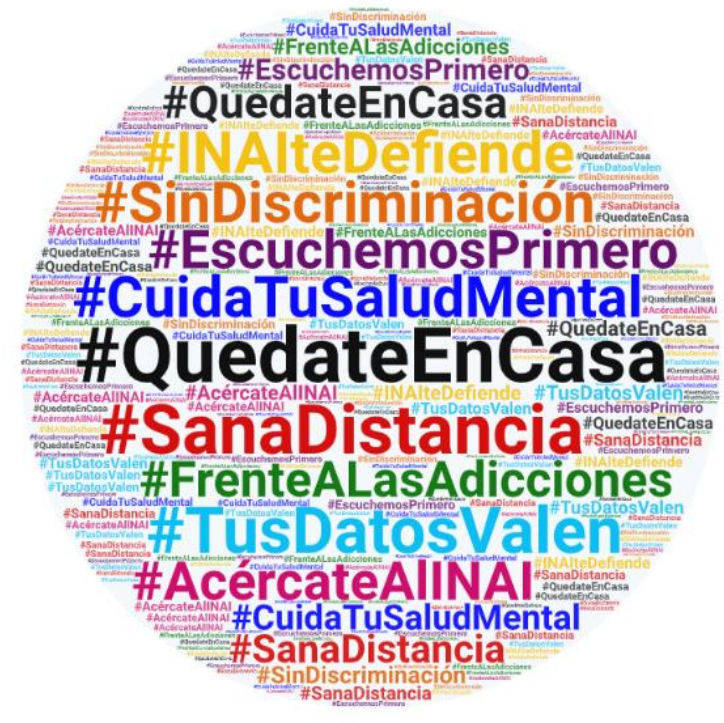

Figura 5. Etiquetas utilizadas en las infografías observadas

Fuente: Elaboración propia basada los datos recuperados de la muestra. 